\title{
SOUNDSCAPE ASSESSMENT OF A MONUMENTAL PLACE: A METHODOLOGY BASED ON THE PERCEPTION OF DOMINANT SOUNDS
}

\author{
Germán Pérez-Martínez a , Antonio J. Torija ${ }^{\text {b }}$, Diego P. Ruiz ${ }^{\text {a }}$ \\ a Information Technology and Communication Research Center (CITIC-UGR), Applied Physics \\ Department, Faculty of Sciences, University of Granada, Spain. \\ ${ }^{\mathrm{b}}$ ISVR, University of Southampton, Highfield Campus, SO17 1BJ Southampton, UK. \\ Tel: +34 958244161 \\ Fax: +34 958243214 \\ E-mail: gperez@ugr.es; A.J.Martinez@soton.ac.uk; druiz@ugr.es
}




\section{Highlights}

- Perception of a given soundscape is driven by the subjectively dominant sounds.

- Proposed methodology is implemented in the Alhambra monumental complex.

- Pleasant dominant sounds are highly correlated with the reported soundscape quality.

- The most influential subjective attributes are those related to quiet natural environments. 


\section{SOUNDSCAPE ASSESSMENT OF A MONUMENTAL PLACE: A METHODOLOGY BASED ON THE PERCEPTION OF DOMINANT SOUNDS}

\section{ABSTRACT}

Some monumental sites have unique soundscapes that deserve to be managed not only by their tourist and cultural value, but also for enhancing the visitors' overall impression. These sites can include a multitude of sound sources within a variety of different locations with geometrically different spaces in size and shape, so that the soundscape assessment could be quite challenging. The hypothesis of this study is that regardless of the complexity of sound sources comprising a given acoustic environment, the perceived soundscape quality is driven primarily by the evaluation of the subjectively dominant sounds. This hypothesis was tested in a field study conducted in a monumental site with historical relevance located in a semi-natural environment (the Alhambra of Granada, Spain). The main finding was that, for a given location, the higher the percentage of visitors reporting a pleasant sound as dominant, the higher the reported soundscape quality and overall impression. Moreover, it was found that: (i) the sounds of birds, water and visitors (voices and footsteps) are the sounds primarily reported as dominant, (ii) the throngs of visitors (human sounds) negatively affect the soundscape quality, (iii) natural sounds increase the reported pleasantness, especially water sounds, which significantly improve the perceived soundscape quality. The practical implication is that, with appropriate information on subjectively dominant sound sources to prioritize corrective actions, soundscape management and its enhancement will require much less time and operational effort than other options for soundscape assessment based on the use of extensive questionnaires. 


\section{INTRODUCTION}

Monuments are constructions/works sharing an artistic, archaeological, historical or similar value. These monuments can be large area enclosures (e.g. Angkor kingdom, Cambodia) or be limited to unique elements in the landscape (e.g. obelisk in Buenos Aires, Argentina).

Monuments of great historical and cultural importance usually become symbols in cities, areas or more extensively of countries, becoming places of great interest and touristic value that receive millions of visitors every year. Furthermore, these monuments can be located in the urban area or in semi-natural or natural areas, which clearly influence the experiences linked to the landscape or environment of the visitor. Our field study has been carried out in the monumental space of historical relevance as is the case of the Alhambra of Granada in Spain (hereinafter referred to as the Alhambra), taken as a representative case study of the proposed methodology for soundscape assessment. This is a monumental space located in a semi-natural area (with little influence of urban noise compared to parks or green areas in the city of Granada), whose surroundings suggest to the visitors to contemplate, walk, rest, and even relax during their visit. This medieval citadel, declared a World Heritage Site in 1984, is the most visited monument in Spain nowadays.

The term "soundscape" has been recently updated (ISO 12913-1, 2014) as the "acoustic environment as perceived or experienced and/or understood by a person or people, in context". The context is therefore a key factor for understanding the perception of a certain acoustic environment, so that it should be included in the soundscape assessment process (Brown, Kang, \& Gjestland, 2011; Hong \& Jeon, 2015). Several works have addressed soundscape perception studies in a variety of environments (contexts), such as urban parks (e.g., Liu, Kang, Behm, \& Luo, 2014), urban squares (e.g. Yang \& Kang, 2005), natural areas (e.g. Miller, 2008), rural 
areas (e.g. Lee, Hong, \& Jeon, 2014), and indoor locations (e.g. Mackrill, Cain, \& Jennings, 2013). While not receiving as much focus there has been some attention paid to historic sites in some research (e.g. Barrigón Morillas, Gómez Escobar, \& Rey Gozalo, 2013).

Traditionally, aesthetic beauty has been one of the main attractions of historical monuments. Nasar (1989) identified the aesthetic quality as an important dimension in the perception of the environment, where the pleasure and beauty represent the most influential dimension in the environmental assessment. But, the assessment of a given environment requires a multidisciplinary approach, and sound plays an essential role (Mace, Bell, \& Loomis, 1999; Southworth, 1969; Yang \& Kang, 2005). A good quality of the soundscape can improve human well-being and offer a more comfortable experience, while allowing to connect the visitors with their environment (Jeon, Lee, Hong, \& Cabrera, 2011; Nilsson et al., 2012), enhancing their overall impression. In this context, good planning and design of the soundscape as another piece of the overall landscape of historical places would undoubtedly help maintain their aesthetic, natural, and cultural qualities, whether expected or existing (Kang et al., 2016).

The soundscape of a given location represents both the acoustic environment as perceived by people and the total inventory of sounds present at such a location (Brown et al., 2011). Kuwano et al. (2002) stated that an acoustic environment is perceived as a collection of individual sounds. This means that the evaluation of a given acoustic environment requires the identification of the individual sounds (Jeon et al., 2011; Kang, 2011; Liu, Kang, Luo, \& Behm, 2013; Szeremeta \& Zannin, 2009). Also, other authors (Axelsson, Nilsson, \& Berglund, 2010; Davies et al., 2013; Matsinos et al., 2008) have suggested that the identification of subjectively dominant sounds is a crucial feature for soundscape classification. The type of sounds present in these historic monumental sites depends on its location (urban, natural or semi-natural environment), as well as 
on its own sounds (sounds coming from the visitors or the characteristic sounds, e.g. water sources). In this sense, the soundscape evaluation depends on the personal preferences to the existing sounds, its loudness and other factors, such as the socio/demographic characteristics (Yu \& Kang, 2010), so that the evaluation of their soundscape could become a challenge.

In monumental areas with great tourist inflow, the noise caused by the visitors tends to be a frequent sound. The perception of human sounds has been widely studied in urban environments, where these sounds have been found to have a either a neutral (e.g. Nilsson \& Berglund, 2006; Yang \& Kang, 2005) or positive (e.g. Szeremeta \& Zannin, 2009) effect; but also in natural spaces where the reduction of human-related sounds enhanced the feeling of soundscape peacefulness and pleasantness (Axelsson et al., 2010; S. Kaplan, 1995; Ulrich et al., 1991). Moreover, monumental and historical sites with adjacent green areas (as in our case study) are sometimes characterized by sound sources, such as birds or water fountains. Aesthetic and sound features of water have been well acknowledged as an important element of the urban environment (Axelsson, Nilsson, Hellström, \& Lundén, 2014; Burmil, Daniel, \& Hetherington, 1999; Whalley, 1988). Water fountains have been found to mask undesirable sounds, thus improving the reported soundscape quality in urban environments (Jeon et al., 2010; You et al., 2010). All these sources emit with a variety of sound levels, thus generating an environmental sound that influences the perception of the soundscape.

Based on these ideas, the hypothesis underlying the present study is that the soundscape quality of historic monumental sites is driven mainly by the evaluation of subjectively dominant sounds. This paper analyses and discusses the extent to which the dominant sounds affect both the subjective quality and other attributes of the soundscape in context. Therefore, this paper 
proposes and develops a methodology for assessing soundscapes based on the perception of subjectively dominant sounds.

\section{METHODOLOGY AND DATA COLLECTION}

This section describes the study area, the data-collection methodology, and how the most representative locations of the Alhambra were selected and then assessed.

\subsection{STUDY AREA}

A series of soundwalks conducted to explore the study area and ensure the selection of a representative sample of the different soundscapes of the Alhambra. It emerged that the Alhambra includes a great diversity of spaces both visually and acoustically. Three descriptive categories of sounds can be found: natural sounds, human sounds (voices and footsteps), and technological sounds. The first two categories of sounds are present in most parts of the monumental complex, while the third one appears in a few locations, such as the case of the walled perimeter and its towers (which are the most exposed to the city of Granada). Its geographical situation and its shape establish a natural barrier for the unwanted sounds coming from the city, e.g. traffic, construction, and restoration works. Figure 1 shows the spatial area comprising the Alhambra and its adjacent spaces: the Alhambra woodland, the city of Granada and the nearby rural areas.

\section{INSERT FIGURE 1 HERE}

The sounds of water constitute one of the main features of the Alhambra, still present in a large portion of the grounds. This can be found in many forms; (burbling water, water jets, cascading water, channels, and even a river below the monument). Figure 2 shows some visual examples. 
The sound of the birds is also very present in most areas of the Alhambra thanks to the adjacent green areas (Alhambra woodland and rural areas) and the vegetation and gardens that exist in its interior space (see Figure 1). Human sounds are also characteristic, due to the number of visitors each year (2,474,231 visits in 2015). This diversity makes this monument a good case study for illustrating the hypothesis of this research.

\section{INSERT FIGURE 2 HERE}

\subsection{SELECTION CRITERIA FOR SAMPLING LOCATIONS}

As mentioned in the previous section, the exploratory study based on a series of soundwalks also aimed to ensure the selection of a representative sample of the different soundscapes in the study area. This exploratory study was undertaken for one week, both when the monument was open (8:00 am - 8:00 pm) and closed (7:00 am - 8:00 am and 8:00 pm - 9:30 pm) to the public. The difference between open and closed hours allowed the investigation of the potential influence of human voices as well as their masking effect. During the closed hours, the environment was dominated by natural sounds with the exception of the Alcazaba area, the walled perimeter, and the towers, which are more exposed to the noise coming from the city. During the open hours, the soundwalks enabled the identification of the locations most likely to be crowded.

The study area includes all the open for visit spaces of the Alhambra, which are classified in 5 large areas referred to as the Alcazaba, the Nasrid Palaces, Palace of Charles V (Carlos V), the Alhambra Alta, and the Generalife. Figure 3 shows the 5 areas comprising the Alhambra site, the 19 selected locations in this research and the main water sound sources near the selected locations. Table 1 also shows a brief description of each location, including general information 
about the characteristics and type of the existing sound sources as well as the typology of the space and its location within each area.

\section{INSERT FIGURE 3 HERE}

In the five areas of the Alhambra, three categories of spaces were identified: courtyards (patios), outdoor spaces, and indoor spaces.

(i) Courtyards: Locations 1, 2, 4, 5, 7, 13, and 14. These patios have gardens ranging in size between $105 \mathrm{~m}^{2}$ and $595 \mathrm{~m}^{2}$. These locations are characterized by having water sounds coming from fountains, with the exception of location 14 (which although having a small bubbling fountain, the sound coming from it was negligible). There is vegetation only in locations 4, 5, 7, and 13 . Locations 1 , 4, and 7 have scenic views of the city.

(ii) Outdoor spaces: Locations, 3, 6, 8, 9, 11, 12, 15, 16, 17, and 19. These wide spaces can be subdivided into two types. The first type are lookouts near the walled perimeter with scenic views of the city and the Alhambra (locations 3, 11, and 16). The second type includes gardens with lush vegetation, benches for the visitors, and the presence of water sounds (with the exception of locations 8, 15, and 19).

(iii) Indoor spaces: Locations 10 and 18. These are small rooms (132 and $64 \mathrm{~m}^{2}$, respectively) open to the outside, i.e. sound coming from outside can be clearly heard. Location 18 has a fountain.

\section{INSERT TABLE 1 HERE}

Once the 19 locations were selected, the specific data-collection points were determined taking into account the following: (i) The data-collection point had to be located on the visitor tour and 
near benches (when available), which were used by the participants to rest and contemplate the sounds in the environment; (ii) The data-collection point represented the overall soundscape, i.e. all the existing sounds (in such location) could clearly be heard. For instance, at a site with a loud fountain, the data-collection point was chosen to record not only the water sound, but also all the other sounds present, in agreement with the criteria i and ii specified above.

\subsection{DATA COLLECTION}

Four hundred visitors at random were asked to take part in the subjective assessment of the monument complex via on-site questionnaires (June-July 2014). Any uncompleted questionnaire were discarded; in this case, 15 were discarded, leaving 385 valid questionnaires corresponding to the 19 locations, with a minimum of 20 questionnaires per location. All the participants, 171 males and 214 females, 16-66 years of age (average 31), were informed about the voluntary character of the study before taking part. Then, they were guided to the assessment point where they filled in the questionnaire. Other socio-demographic data of the participants, such as their education level (primary, secondary and higher level) or residential status (spanish or nonspanish) were also collected in the questionnaire.

The questionnaire used for subjectively assessing the soundscape was composed of 3 main sections:

(i) In the first section, the participants were asked to report the sounds they heard (i.e. identified sounds). Each sound identified was evaluated in terms of how pleasant it was perceived at that time and in that context, using a five-point scale, in which 1 was "unpleasant" and 5 was "pleasant". Moreover, the participants were asked whether they perceived a subjectively dominant sound in the soundscape, and if so, which. 
178 (ii) In the second section, the participants assessed the quality of the soundscape, the perceived loudness, the quality of the visual environment and the overall impression using a visual-analogue scale, with the left-hand end equal to 0 (none) and the right-hand end equal to 10 (greatest).

(iii) In the third section a set of 12 semantic attributes were evaluated using a visual-analogue scale from 0 to 10 . Thus, the participants used this scale ( 0 was "totally disagree" and 10 was "totally agree") to indicate their degree of agreement with each subjective attribute for the soundscape. The subjective attributes were: pleasant, acute, calm, varied, near, natural, comfortable, relaxed, steady, usual, reverberant, and smooth.

The questionnaire, and especially the semantic attributes chosen, was based on previous studies (Axelsson et al., 2014; Jeon, Lee, You, \& Kang, 2012; Nilsson \& Berglund, 2006; Yang \& Kang, 2005; Hall, Irwin, Edmondson-Jones, Phillips, \& Poxon, 2013; Jeon et al., 2011; Kang \& Zhang, 2010; Raimbault, 2006), Those attributes covering the positive aspects of the soundscape were chosen, as well as those related to spatial, temporal, or variety of sound sources.

Although an analysis based on sound level measurements was not the main objective of this research, sound levels (dBA) were also recorded in order to obtain a guidance of the physical sound levels at each location. To accomplish this, 3 binaural recordings (Squadriga I recorder and BHS I headset / microphone unit) were made at each location. The sound-level of each acoustical measure was calculated as the averaged equivalent-energy sound-pressure level of the left and right channels during a measuring time interval enough to ensure sound level indicator stability $\left(L_{A e q, 5 \min }\right)$. Finally, an energy averaging of the 3 acoustic measurements in each location was performed in order to obtain a sound-level value (dBA) representative of each location. 
Both subjective and acoustical data were collected at each location for 19 days during summertime. After consultation with the Alhambra staff, a peak time interval from 10:00 am to 12:00 pm was selected. In this time interval, both the visitor flow and the environmental conditions such as lighting, temperature, etc. remained practically stable between days, (data supplied by the National Agency of Meteorology, Granada-Cartuja stationhttps://sede.aemet.gob.es).

\section{RESULTS}

\subsection{IDENTIFICATION AND DESCRIPTIVE ASSESSMENT OF SOUNDS}

In each location, the participants identified and then evaluated all the sounds they were able to hear. Figure 4 shows the list of sounds identified and the percentage of participants identifying each sound source. Note that the sounds identified by a percentage of participants less than $1 \%$ are omitted. Figure 5 shows the subjective assessment of each individual sound (in terms of pleasantness) for the entire set of locations. The data were labeled as: "1 and 2" unpleasant, "3" neutral, and "4 and 5" pleasant.

\section{INSERT FIGURE 4 HERE}

In the overall set of locations selected, the participants identified 15 different sounds, three of which (people talking, birds, and water) were identified by more than $50 \%$ of the participants (Figure 4). The sound generated by people was the sound most frequently identified, given the crowds of visitors present each day. The sound of the birds was the second most frequently identified sound, since the walled and landscaped areas of the Alhambra woodland surrounding the monument act as refuges for many species of birds. The sound of water occupied third place, as water is present throughout the Alhambra in many forms (as described above). 


\section{INSERT FIGURE 5 HERE}

The vast majority of the technological sounds such as urban road traffic (85\% of participants), air traffic (78\%), construction works (75\%), Walkie-Talkies (used by Alhambra security personal) or photo cameras (66\%), were evaluated by a high percentage of respondents as unpleasant, with the exception of sounds coming from church bells that were considered pleasant (64\%). Human voices, such as the humans speaking, and the sound of footsteps were also evaluated by the majority as unpleasant (55\% and 50\% respectively), although a high percentage also evaluated them as neutral (44\% and 33\% respectively).

Meanwhile, natural sounds, such as those coming from water (84\%), birds (66\%), wind (66\%), and the leaves of the trees (62\%) were evaluated as pleasant. However, other natural sounds such as dogs (57\%) and frogs (71\%) were evaluated as unpleasant, although the results are not conclusive since they were identified by a reduced proportion of participants.

\subsection{SUBJECTIVELY DOMINANT SOUNDS}

Figure 6 shows the percentage of participants reporting the identifying sound as subjectively dominant. Again the identified sounds most frequently reported as subjectively dominant were those of people, water, and birds, well above the other sounds (identified by $90 \%$ of visitors). Among the identified sounds, the water sounds were the most frequently reported as subjectively dominant, followed by people and birds sounds. This implied that, despite that the people sounds were the most frequently identified (Figure 4), the water sounds were reported as most relevant in terms of subjective dominance. 
An acoustic environment consists of different types of sounds, each sound contributing of different ways to the overall perceived loudness. When a sound is considered subjectively dominant, it usually assumes greater relevance in terms of perceived loudness than other sounds heard in this place. In this sense and from our results, it appears appropriate to consider the dominant sounds as an important descriptor within the evaluation of the quality of the soundscape within their context.

250

251

\subsection{RELATIONSHIP BETWEEN DOMINANT SOUNDS AND OTHER REPORTED INDICATORS}

In an effort to validate the research hypothesis, a correlation analysis was performed between the subjectively dominant sounds and the reported soundscape quality. The relationship between the subjectively dominant sounds and the reported loudness, reported visual quality, the reported overall impression, and sound-levels (dBA) was also studied. For the purposes of the subsequent analyses, and because it is a dichotomy problem (i.e. either pleasant or unpleasant sounds), only subjectively dominant sounds evaluated as pleasant (water, birds, wind, and cicadas), and consequently contributing to a positive soundscape, were considered. Table 2 shows, for each of the 19 studied locations, the percentage of participants reporting any pleasant sound as subjectively dominant, and the average value of the reported loudness, soundscape quality, visual quality, overall impression, and sound-levels (dBA). As shown in Table 2, soundscape-quality scores were lower than those for visual quality and overall impression at all locations, and the scores of visual quality were higher than the overall impression in almost all locations. 
From Table 2 it is worth noting that although $100 \%$ of the participants reported pleasant sounds as subjectively dominant in location 2, the score of the soundscape quality (6.3 points) was not comparable with that of other locations that reported a similar percentage. For example, in locations $4,7,13,16$ and 17 , between $90 \%$ and $100 \%$ of the participants reported pleasant sounds as subjectively dominant, and accordingly these locations obtained soundscape quality scores between 7 and 8 points, as expected. This fact could be explained by two factors: the typology of pleasant sounds that were identified as subjectively dominant in localization 2 and the perceived loudness in that location. The highest perceived loudness was reported in this location (see Table 2), and here the bird sounds (identified as subjectively dominant by 95\% of participants) was perceived as less pleasant (3.3 points on a scale ranging from 1 to 5 ) than the sound of birds in other locations, for example in location 12 was scored as 4.2 points (1-5 scale). This difference was due to the species of birds that frequent location 2. This will be further discussed in Section IV.

Table 3 shows the Pearson's correlation coefficients between the percentage of participants reporting a pleasant sound as subjectively dominant and the average value of the reported loudness, soundscape quality, visual quality, overall impression, and sounds-levels (dBA). Before the Pearson's correlation analysis was conducted, the normality of the data was checked using the Kolmogorov-Smirnov test. The percentage of participants reporting a pleasant sound as subjectively dominant is highly correlated with the reported soundscape quality and overall impression, supporting the hypothesis that the soundscape quality is driven by the sounds perceived as subjectively dominant, and therefore that those sounds play a key role in the soundscape quality assessment. Also noteworthy is the fairly good correlation between the percentage of participants reporting a pleasant sound as subjectively dominant and the reported 
visual quality. This might be interpreted as the configuration of spaces also determine the type of sounds in them, since places with abundant vegetation and water fountains or waterfalls are usually linked with both pleasant dominant sounds and good visual quality. In addition, it can be observed that sound level shows a good correlation with the perceived loudness, but not with the other descriptors, including soundscape quality. This result suggests that the evaluation of soundscapes cannot be addressed only considering measured sound levels, but other factors such as the perception of dominant sounds (as proposed in this work) have to be taken into account.

INSERT TABLE 3 HERE

\subsection{SOUNDSCAPE ASSESSMENT AS A FUNCTION OF THE SUBJECTIVELY DOMINANT SOUNDS}

For further analysis of the influence of the subjectively dominant sounds on the soundscape quality and on the 12 semantic attributes, the set of locations were classified on the basis of the subjectively dominant sound. Note that a subjectively dominant sound was assigned to a given location where at least $50 \%$ of the participants considered such a sound as dominant in the location. Three groups of locations were set: (i) people - people sounds as dominant (locations 10, 15, 18, and 19), (ii) water - water sounds as dominant (locations 4, 5, 6, 7, 9, 13, 16, and 17), and (iii) birds - birds sounds as dominant (locations 2, 3, 11, 12, and 14). Locations 1 and 8 cannot be reliably classified as corresponding to any group.

After each case was assigned to a group (people, water or birds), a Kruskal-Wallis test was applied to check for significant differences in the soundscape quality and 12 attributes among the 3 groups. For variables where significant differences were found, a Mann-Whitney test was applied in order to conduct pairwise comparisons for significant differences between the groups 
"people", "water", and "birds" (see Table 4). The Kruskal-Wallis tests show significant differences between the three groups for the soundscape quality and the subjective attributes "pleasant", "near", "natural", "comfortable", "relaxed", "steady", "usual", and "smooth". For all other subjective attributes, "acute", "calm", "varied" and "reverberant" no significant differences were found. In addition, the same test was used to analyze the effects of socio-demographic factors on the soundscape quality assessment for the three groups of locations. The analyzed factors were: age (divided into 5 ranges: 16-20, 21-30, 31-40, 41-50, 51-66), gender (male and female); education (primary, secondary and higher level) and residential status (Spanish and nonSpanish). The test did not show significant differences for any of the mentioned factors (pvalue $>0.05$ ), suggesting that these socio-demographic factors did not affect the assessment of the soundscape quality in this specific context.

\section{INSERT TABLE 4 HERE}

\section{INSERT FIGURE 7 HERE}

Figure 7 lists the average values of the reported soundscape quality and the 12 subjective attributes for the grouped locations with people, water, and birds sounds as subjectively dominant. Table 4 and Figure 7 show that the group subjectively dominated by the water sounds scores significantly higher than do the group subjectively dominated by people sounds in the attributes related to the positive aspects of the soundscape, i.e. "pleasant", "natural", "comfortable", "relaxed", and "smooth", and also in those describing sensations related spatial and temporal variation of the sound, i.e. "near" and "steady". The group dominated by the birds sounds also scores significantly higher than do the group dominated by the people sounds in the attributes related to the positive aspects of the soundscape, i.e. "pleasant", "natural", 
"comfortable", "relaxed", but do not in those describing sensations related to the spatial and temporal variation of the sound. The group dominated by the people sounds only scores significantly higher than do group dominated by the water sounds in the attribute "usual", which relates to the commonness of the sounds. Therefore, those locations where the people sounds were subjectively dominant receive the lowest scores in all positive aspects of the soundscape. The group dominated by the water sounds scores significantly higher than do the group dominated by birds sounds in the attributes related to the positive aspects of the soundscape, i.e. "pleasant", "natural", "relaxed", and "smooth", and also in those describing sensations related spatial and temporal variation of the sound, i.e. "near" and "steady". Also the average soundscape quality shows statistically significant differences, reaching the highest score in the locations dominated by the sounds of water, followed by the locations dominated by birds and finally those dominated by the people.

Moreover, the correlations between the quality of the soundscape and the 12 attributes were analyzed. It should be noted that the average values of the 19 locations were used in this analysis. Spearman's coefficients were calculated between soundscape quality and subjective attributes (Table 5).

\section{INSERT TABLE 5 HERE}

As can be seen, the soundscape quality correlates well with the attributes "pleasant", "natural", "comfortable", and "relaxed", which refer to the positive aspects of the soundscape. The attributes "steady" and "smooth" shows a lower correlation. The attribute "usual" shows a significant negative correlation with the soundscape quality. In addition, the attribute "calm" has 
a low correlation (compared to the other attributes), while "acute", "varied", "near", and "reverberant" appear not to be correlated with the reported soundscape quality.

\section{DISCUSSION}

On the basis of the results found in the preceding section, the following can be inferred:

\section{a) Relationship between the reported quality of the soundscape and the subjectively dominant sounds}

The different types of sounds identified in the Alhambra monumental complex were reduced to 6 types of subjectively dominant sounds (see Figure 4 and 5). The percentage of participants that reported pleasant sounds as subjectively dominant was highly correlated with the reported quality of the soundscape quality and the overall impression of the visitor (see Table 3). In the case study of the Alhambra complex, 3 of these 6 types of subjectively dominant sounds were strongly relevant in assessing the soundscape (water, birds, and people), since the $90 \%$ of the visitors reported one of these sounds as subjectively dominant. The results showed that Figure 7 and Table 4 support the assumption that the reported quality of the soundscape and their subjective attributes are strongly affected by the type of sounds that dominate that site.

The categorical variable "dominant sounds" was previously used by other authors in order to establish relationships with some specific attributes to the soundscape. For example, Axelsson et al. (2010) found that the soundscape dominated by technological sounds had a negative correlation with pleasantness, while human and natural sounds correlated positively with eventfulness and pleasantness, respectively. Matsinos et al. (2008) also studied dominant sound categories and the effect of the local landscape characteristics on sound perception. They showed 
that the combination of the visual landscape information and its acoustic profile enhances our perception and understanding of our environment.

The results presented in this paper corroborate the importance of the subjectively dominant sounds for the assessment of the soundscape quality, justifying the use of perception of dominant sounds for managing the soundscape quality. It should be noted that the use of dominant sounds not only allows the estimation of the soundscape quality, but also might provide key information for the management and conservation of soundscapes, i.e. in terms of what sounds should be conserved/promoted and what sounds should be avoided/reduced; or what are the constraint factors ("positive" perceived or "negative" perceived dominant sounds) for improving soundscape quality. Such information concerning sound quality is valuable and useful for technicians responsible for managing and conserving public places.

\section{b) Quality of the soundscape and subjective attributes in terms of dominant sounds}

The score of the reported soundscape quality significantly worsened when the human sounds are subjectively dominant (i.e. reported as subjectively dominant by more than $50 \%$ of respondents) compared to when water or birds sounds are. In this case, the attributes "pleasant", "natural", "comfortable", "relaxed", and "steady" also score poorly (Figure 7, Table 4). The aural presence of crowds in certain locations $(10,15,18$ and 19) deteriorated the soundscape quality. This result could be related to the visitor expectations of the specified use to that place. Carles et al. (1999) found that natural or natural-urban environments with presence of natural sounds are particularly sensitive to human sounds, and it is suggested the need to preserve those unique soundscapes, especially when they are protected spaces, cultural landscapes, parks and green areas. In this 
sense, Kogan et al. (2017) suggested that human sounds are usually described as annoying in spaces used for walking or resting when their level tends to mask other natural sounds.

This study suggests that, in the context of monumental or historical sites of great tourist interest (of the same type of our study case as defined in the introduction section), the human sounds affect the soundscape quality mainly by masking pleasant or relaxing sounds. In fact, in some cases, the respondents were extremely negative toward the attitude of the other visitors, clearly expressing their annoyance and discomfort with statements such as "this is not an amusement park". These comments agreed with the evaluation of the human sounds in this context (Figure 5 and 7), suggesting that at monumental or historical sites of great tourist interest (and so widely visited along with many people), crowds can disturb the soundscape for many visitors.

Furthermore, in these type of areas where this research is focus on visitors could expect a natural and relaxing environment where they can seek cognitive restoration (R. Kaplan \& Kaplan, 1989). Thus, human sounds can feel intrusive, upsetting visitor tranquility. This agrees with Iglesias Merchan et al. (2014), who found remarkable soundscape degradation due to voices of visitors in a national park, where the reported annoyance due to the visitors themselves was even considered as high as the annoyance caused by airplanes overhead or road traffic nearby.

Whenever water sounds predominated (i.e. the water sound was reported as subjectively dominant by more than $50 \%$ of the respondents) the reported soundscape quality significantly raises its scores compared to environments where the human or birds sounds were reported as dominant. The attributes "pleasant", "near", "natural", "comfortable", "relaxed", "steady", and "smooth" also achieve good scores (Figure 7, Table 4). In the context under study, water sounds have a clearly positive effect, as established by different authors (e.g. Axelsson et al., 2014; Carles et al., 1999; Pheasant et al., 2008; Torija et al., 2013). 
In locations where bird sounds were reported to be subjectively dominant by more than $50 \%$ of the respondents, the value of reported soundscape quality, and of the attributes "pleasant", "natural, "comfortable", and "relaxed" (positive aspects of the soundscape) is found to be significantly higher than in locations where people sounds were reported as dominant. However, in locations with birds sounds subjectively dominating, the value of reported soundscape quality, and of the attributes "pleasant", "near", "natural", "comfortable", "relaxed", "steady", and "smooth" is significantly lower than in locations with water sounds reported as subjectively dominant. This seems to indicate that, although birds sounds are widely acknowledged as positive and valued (cf. Carles et al., 1999; Hao, Kang, \& Wörtche, 2016; Pilcher, Newman, \& Manning, 2008), in the context under study water sounds are more appreciated for improving the soundscape quality. It is interesting to note that at location 2, the perception of bird sounds varied with respect to the perception of birds from other locations. As commented before, this difference was due to the bird species appearing in this location. Birds living in the plasterwork edge of location 2 (common swift) generate a scratchy chirp (loud and acute sound) which was considered less pleasant than softer and melodic birdsongs or chirpings of species common in other spaces, such as the blackbird, nightingale, or chaffinch. In the period of the assessment, there was a conservation program in the Alhambra intended to move these species toward outlying areas of the Nasrid Palaces since they were considered to be disturbing.

\section{c) Relationship between the soundscape quality and the subjective attributes evaluated}

The reported soundscape quality strongly correlates with the attribute "pleasant" (Table 5), perhaps because this adjective refers to an emotion or feeling by which individuals assess the environmental sounds in terms of pleasure (Aletta, Kang, \& Axelsson, 2016; Axelsson et al., 2010). Similarly, the soundscape quality refers to how appropriate the soundscape is and the 
amount of pleasure it stirs in the visitor. The soundscape quality, experienced in the context of the monumental site under study, strongly depends on the attributes "relaxed", "natural", and "comfortable" (Table 5), which are characteristic of natural spaces free from loud traffic noises.

A high Spearman's correlation is found between the reported soundscape quality and the attributes "smooth" and "steady", which refer to the temporal variation of loudness, and (Table 5), indicating that they are somehow influential in the composition of the overall soundscapequality concept. The attribute "usual" also shows a significant negative correlation, suggesting that unusual or unexpected sounds in monumental spaces can be attractive for visitors and thereby improve the soundscape quality. The attribute "calm" do not strongly correlate with soundscape quality (compared to the above mentioned attributes) perhaps because this attribute is considered to concern loudness perception, and wherever the natural sounds and/or human voices physically dominate, this possible indicator of soundscape quality tends to be unreliable.

The attributes "near", "reverberant", "acute", and "varied", which are related to the spatial sensations and the variety of the sounds in the space, correlates poorly with the reported soundscape quality. This result is in line with Jeon et al. (2011), who analyzed the attribute "reverberant" in terms of preference and determined that this attribute is not a good indicator in an urban soundscape and that it plays a minor role in social preference for soundscapes.

\section{CONCLUSIONS}

Monumental and historical sites have remarkable tourist and cultural interest and host millions of visitors every year. The assessment and management of soundscapes at these places and related areas is important in order to foster a better visitor experience. As a representative case of these 
sites, a field study was conducted in the Alhambra of Granada, which is characterized by a rich diversity of spaces and well as a variety of sound sources.

The procedure followed for soundscape assessment was follows: firstly, the sounds present at the scene were analyzed, focusing on the sounds reported as subjectively dominant. The percentage of visitors reporting a pleasant sound as dominant shows a high correlation with the reported quality and the overall impression of the visitor. Then, based on these results, the different locations of the monumental complex were classified according to their dominant sounds (3 dominant sounds in this case study). In a third step, several comparisons were made between them to draw conclusions. The results clearly show that the reported subjective attributes of a specific soundscape were affected by the type of sound that dominated at each location.

These results support the research hypothesis that the perception of a given soundscape is driven by the evaluation of the subjectively dominant sounds. Therefore, this research suggests the use of this variable to simplify the soundscape assessment procedure, and thus reducing the operational time and effort required to accomplish this task. This is important for managing soundscapes, since, for instance, for the improvement of a given soundscape, the subjectively dominant sounds should first be identified, and then, specific actions can be implemented to eliminate or reduce those perceived as negative and to promote those perceived as positive.

Finally, some other specific conclusions can be drawn from this work:

(i) The most influential subjective attributes of soundscape quality are those related to quiet natural environments, i.e. "pleasant", "relaxed", "natural”, and "comfortable". The attribute "calm" was not always associated with good soundscape quality due to the importance of the origin of the sound (i.e. natural or man-made sounds). 
(ii) The presence of crowds has a clearly negative impact. When human sounds were identified as subjectively dominant by more than $50 \%$ of the respondents, the quality of the soundscape was significantly reduced. This type of soundscapes should then be managed by avoiding crowds and controlling people flux in these areas.

(iii) Natural sounds were usually evaluated as positive, except in certain cases where unpleasant bird sounds dominate the sound environment. The identification of water sounds as subjectively dominant was highly related to positive soundscape quality. effect. 


\section{References}

Aletta, F., Kang, J., \& Axelsson, Ö. (2016). Soundscape descriptors and a conceptual framework for developing predictive soundscape models. Landscape and Urban Planning, 149, 65-74. http://doi.org/10.1016/j.landurbplan.2016.02.001

Axelsson, Ö., Nilsson, M. E., \& Berglund, B. (2010). A principal components model of soundscape perception. The Journal of the Acoustical Society of America, 128(5), 28362846. http://dx.doi.org/10.1121/1.3493436

Axelsson, Ö., Nilsson, M. E., Hellström, B., \& Lundén, P. (2014). A field experiment on the impact of sounds from a jet-and-basin fountain on soundscape quality in an urban park. Landscape and Urban Planning, 123(0), 49-60. http://dx.doi.org/10.1016/j.landurbplan.2013.12.005

Barrigón Morillas, J. M., Gómez Escobar, V., \& Rey Gozalo, G. (2013). Noise source analyses in the acoustical environment of the medieval centre of Cáceres (Spain). Applied Acoustics, 74(4), 526-534. http://doi.org/10.1016/j.apacoust.2012.10.001

Brown, A. L., Kang, J., \& Gjestland, T. (2011). Towards standardization in soundscape preference assessment. Applied Acoustics, 72(6), 387-392. http://dx.doi.org/10.1016/j.apacoust.2011.01.001

Burmil, S., Daniel, T. C., \& Hetherington, J. D. (1999). Human values and perceptions of water in arid landscapes. Landscape and Urban Planning, 44(2-3), 99-109. http://dx.doi.org/10.1016/S0169-2046(99)00007-9

Carles, J. L., Barrio, I. L., \& de Lucio, J. V. (1999). Sound influence on landscape values. Landscape and Urban Planning, 43(4), 191-200. http://dx.doi.org/10.1016/S01692046(98)00112-1

Davies, W. J., Adams, M. D., Bruce, N. S., Cain, R., Carlyle, A., Cusack, P., ... Poxon, J. (2013). Perception of soundscapes: An interdisciplinary approach. Applied Acoustics, 74(2), 224-231. http://doi.org/10.1016/j.apacoust.2012.05.010

Hall, D. A., Irwin, A., Edmondson-Jones, M., Phillips, S., \& Poxon, J. E. W. (2013). An exploratory evaluation of perceptual, psychoacoustic and acoustical properties of urban soundscapes. Applied Acoustics, 74(2), 248-254. http://dx.doi.org/10.1016/j.apacoust.2011.03.006

Hao, Y., Kang, J., \& Wörtche, H. (2016). Assessment of the masking effects of birdsong on the road traffic noise environment. The Journal of the Acoustical Society of America, 140(2). http://dx.doi.org/10.1121/1.4960570

Hong, J. Y., \& Jeon, J. Y. (2015). Influence of urban contexts on soundscape perceptions: A structural equation modeling approach. Landscape and Urban Planning, 141, 78-87. http://doi.org/10.1016/j.landurbplan.2015.05.004

Iglesias Merchan, C., Diaz-Balteiro, L., \& Soliño, M. (2014). Noise pollution in national parks: Soundscape and economic valuation. Landscape and Urban Planning, 123, 1-9. 
http://doi.org/10.1016/j.landurbplan.2013.11.006

International Organization for Standardization. (2014). ISO 12913-1:2014 acousticssoundscape — part 1: definition and conceptual framework. Geneva: ISO.

Jeon, J. Y., Lee, P. J., Hong, J. Y., \& Cabrera, D. (2011). Non-auditory factors affecting urban soundscape evaluation. The Journal of the Acoustical Society of America, 130(6), 37613770. http://dx.doi.org/10.1121/1.3652902

Jeon, J. Y., Lee, P. J., You, J., \& Kang, J. (2010). Perceptual assessment of quality of urban soundscapes with combined noise sources and water sounds. The Journal of the Acoustical Society of America, 127(3), 1357-1366. http://dx.doi.org/10.1121/1.3298437

Jeon, J. Y., Lee, P. J., You, J., \& Kang, J. (2012). Acoustical characteristics of water sounds for soundscape enhancement in urban open spaces. The Journal of the Acoustical Society of America, 131(3), 2101-2109. http://dx.doi.org/10.1121/1.3298437

Kang, J. (2011). Noise Management: Soundscape Approach. Encyclopedia of Environmental Health, 174-184. http://dx.doi.org/10.1016/B978-0-444-52272-6.00260-9

Kang, J., Aletta, F., Gjestland, T. T., Brown, L. A., Botteldooren, D., Schulte-Fortkamp, B., ... Lavia, L. (2016). Ten questions on the soundscapes of the built environment. Building and Environment, 108, 284-294. http://doi.org/10.1016/j.buildenv.2016.08.011

Kang, J., \& Zhang, M. (2010). Semantic differential analysis of the soundscape in urban open public spaces. Building and Environment, 45(1), 150-157. http://dx.doi.org/10.1016/j.buildenv.2009.05.014

Kaplan, S. (1995). The restorative benefits of nature: Toward an integrative framework. Journal of Environmental Psychology, 15(3), 169-182. http://doi.org/10.1016/0272-4944(95)900012

Kaplan, R., \& Kaplan, S. (1989). The experience of nature: A psychological perspective. Cambridge: University Press Cambridge.

Kogan, P., Turra, B., Arenas, J. P., \& Hinalaf, M. (2017). A comprehensive methodology for the multidimensional and synchronic data collecting in soundscape. Science of The Total Environment, 580, 1068-1077. http://doi.org/10.1016/j.scitotenv.2016.12.061

Kuwano, S., Seiichiro, N., Kato, T., \& Hellbrueck, J. (2002). Memory of the loudness of sounds and its relation to overall impression. In Forum Acusticum, Seville, Spain.

Lee, P. J., Hong, J. Y., \& Jeon, J. Y. (2014). Assessment of rural soundscapes with high-speed train noise. The Science of the Total Environment, 482-483, 432-9. http://doi.org/10.1016/j.scitotenv.2013.07.026

Liu, J., Kang, J., Behm, H., \& Luo, T. (2014). Effects of landscape on soundscape perception: Soundwalks in city parks. Landscape and Urban Planning, 123(0), 30-40. http://dx.doi.org/10.1016/j.landurbplan.2013.12.003 
Liu, J., Kang, J., Luo, T., \& Behm, H. (2013). Landscape effects on soundscape experience in city parks. Science of The Total Environment, 454-455(0), 474-481. http://dx.doi.org/10.1016/j.scitotenv.2013.03.038

Mace, B.L., Bell, P.A., \& Loomis, R.J. (1999). Aesthetic, Affective, and Cognitive Effects of Noise on Natural Landscape Assessment. Society \& Natural Resources, 12(3), 225-242. http://doi.org/10.1080/089419299279713

Mackrill, J., Cain, R., \& Jennings, P. (2013). Experiencing the hospital ward soundscape: Towards a model. Journal of Environmental Psychology, 36(0), 1-8. http://dx.doi.org/10.1016/j.jenvp.2013.06.004

Matsinos, Y. G., Mazaris, A. D., Papadimitriou, K. D., Mniestris, A., Hatzigiannidis, G., Maioglou, D., \& Pantis, J. D. (2008). Spatio-temporal variability in human and natural sounds in a rural landscape. Landscape Ecology, 23(8), 945-959.

Miller, N. P. (2008). US National Parks and management of park soundscapes: A review. Applied Acoustics, 69(2), 77-92. http://dx.doi.org/10.1016/j.apacoust.2007.04.008

Nasar, J. L. (1989). Public Places and Spaces. In I. Altman \& E. H. Zube (Eds.), Perception, cognition, and evaluation of urban places (pp. 31-56). Boston, MA: Springer US. http://doi.org/10.1007/978-1-4684-5601-1_3

Nilsson, M. E., \& Berglund, B. (2006). Soundscape quality in suburban green areas and city parks. Acta Acustica United with Acustica, 92(6), 903-911.

Nilsson, M. E., Jeon, J. Y., Rådsten-Ekman, M., Axelsson, Ö., Hong, J. Y., \& Jang, H. S. (2012). A soundwalk study on the relationship between soundscape and overall quality of urban outdoor places. The Journal of the Acoustical Society of America, 131(4), 3474. http://doi.org/10.1121/1.4709105

Pheasant, R., Horoshenkov, K., Watts, G., \& Barrett, B. (2008). The acoustic and visual factors influencing the construction of tranquil space in urban and rural environments tranquil spaces-quiet places? The Journal of the Acoustical Society of America, 123(3), 1446-1457. http://dx.doi.org/10.1121/1.2831735

Pilcher, E. J., Newman, P., \& Manning, R. E. (2008). Understanding and Managing Experiential Aspects of Soundscapes at Muir Woods National Monument. Environmental Management, 43(3), 425-435. http://doi.org/10.1007/s00267-008-9224-1

Raimbault, M. (2006). Qualitative judgements of urban soundscapes: Questionning questionnaires and semantic scales. Acta Acustica United with Acustica, 92(6), 929-937.

Southworth, M. (1969). The Sonic Environment of Cities. Environment and Behavior, 1(1), 4970. http://dx.doi.org/10.1177/001391656900100104

Szeremeta, B., \& Zannin, P. H. T. (2009). Analysis and evaluation of soundscapes in public parks through interviews and measurement of noise. Science of The Total Environment, 407(24), 6143-6149. http://dx.doi.org/10.1016/j.scitotenv.2009.08.039 
Torija, A. J., Ruiz, D. P., \& Ramos-Ridao, A. F. (2013). Application of a methodology for categorizing and differentiating urban soundscapes using acoustical descriptors and semantic-differential attributes. Journal of the Acoustical Society of America, 134(1), 791802. http://dx.doi.org/10.1121/1.4807804

Ulrich, R. S., Simons, R. F., Losito, B. D., Fiorito, E., Miles, M. A., \& Zelson, M. (1991). Stress recovery during exposure to natural and urban environments. Journal of Environmental Psychology, 11(3), 201-230. http://doi.org/10.1016/S0272-4944(05)80184-7

Whalley, J. M. (1988). Water in the landscape. Landscape and Urban Planning, 16(1-2), 145162. http://doi.org/10.1016/0169-2046(88)90040-0

Yang, W., \& Kang, J. (2005). Soundscape and sound preferences in urban squares: a case study in Sheffield. Journal of Urban Design, 10(1), 61-80. http://dx.doi.org/10.1080/13574800500062395

You, J., Lee, P. J., \& Jeon, J. Y. (2010). Evaluating water sounds to improve the soundscape of urban areas affected by traffic noise. Noise Control Engineering Journal, 58(5), 477-483.

Yu, L., \& Kang, J. (2010). Factors influencing the sound preference in urban open spaces. Applied Acoustics, 71(7), 622-633. http://dx.doi.org/10.1016/j.apacoust.2010.02.005 


\section{List of Tables}

Table 1. Selected locations for data collection, and the most characteristic sound sources and area in the Alhambra complex (http://www.alhambra-patronato.es). Traffic: traffic sounds; Water: water sources, including falling and flowing water; Birds: sounds of birds; People: sounds from crowds.

Table 2. Percentage of participants reporting a pleasant sound as subjectively dominant and average value for the subjective questions "soundscape quality", "visual quality", "overall impression", "reported loudness" and "sound-levels (dBA)" in each of the 19 locations.

Table 3. Pearson's correlation (Pearson's r) between the percentage of participants reporting a pleasant sound as subjectively dominant and average value for the subjective questions "soundscape quality", "visual quality", "overall impression", "reported loudness" and "soundlevels (dBA)".

Table 4. Results (p-value) of the Kruskal-Wallis test (comparisons between the groups "people", "water", and "birds") and Mann-Whitney U test (pairwise comparisons people-water, peoplebirds, and water-birds ).

Table 5. Spearman's correlation (Spearman's Rho) between the reported quality of the soundscape and subjective attributes. 
Table 1

\begin{tabular}{llcccccl}
\hline No. & Location & Traffic & Birds & Water & People & Type of Space & Area \\
\hline 1 & Patio de la Reja & Yes & Yes & Fountain & Yes & Courtyard & Nasrid Palaces \\
2 & Patio de los Leones & No & Yes & Fountain & Yes & Courtyard & Nasrid Palaces \\
3 & Torre del Cubo & Yes & Yes & Water Flowing & No & Outdoor Space & Alcazaba \\
4 & Jardín de los Adarves & Yes & Yes & Fountain & No & Courtyard & Alcazaba \\
5 & Patio de Lindaraja & No & No & Fountain & Yes & Courtyard & Nasrid Palaces \\
6 & Partal & No & Yes & Water Flowing & Yes & Outdoor Space & Alhambra Alta \\
7 & Patio de la Acequia & No & No & Fountain & Yes & Courtyard & Generalife \\
8 & Jardines de la Medina & No & Yes & No & No & Outdoor Space & Alhambra Alta \\
9 & Jardines Bajos & No & Yes & Fountain & No & Outdoor Space & Generalife \\
10 & Salón de Embajadores & No & No & No & Yes & Indoor Space & Nasrid Palaces \\
11 & Torre de la Vela & Yes & Yes & No & No & Outdoor Space & Alcazaba \\
12 & Entrance to Generalife & No & Yes & Waterfalls & No & Outdoor Space & Generalife \\
13 & Patio de la Sultana & No & Yes & Fountain & No & Courtyard & Generalife \\
14 & Cuarto Dorado & No & No & No & Yes & Courtyard & Nasrid Palaces \\
15 & Entrance to la Medina & Yes & Yes & No & No & Outdoor Space & Alhambra Alta \\
16 & Torre de las Infantas & No & Yes & Waterfalls & No & Outdoor Space & Alhambra Alta \\
17 & Jardines Altos & No & No & Fountain & Yes & Outdoor Space & Generalife \\
18 & Sala de Dos Hermanas & No & No & Fountain & Yes & Indoor Space & Nasrid Palaces \\
19 & Las Placetas & No & Yes & No & Yes & Outdoor Space & Carlos V \\
\hline
\end{tabular}


Table 2

\begin{tabular}{ccccccc}
\hline No. & $\begin{array}{c}\text { \% Participants } \\
\text { reporting a } \\
\text { pleasant sounds } \\
\text { as subjectively } \\
\text { dominant }\end{array}$ & $\begin{array}{c}\text { Soundscape } \\
\text { quality }\end{array}$ & $\begin{array}{c}\text { Overall } \\
\text { impression }\end{array}$ & $\begin{array}{c}\text { Visual } \\
\text { quality }\end{array}$ & $\begin{array}{c}\text { Reported } \\
\text { loudness }\end{array}$ & $\begin{array}{c}\text { Sound-levels } \\
\text { (dBA) }\end{array}$ \\
\hline 1 & 55.0 & 6.9 & 8.1 & 8.8 & 4.6 & 64.5 \\
2 & 100.0 & 6.3 & 7.9 & 8.8 & 6.1 & 68.3 \\
3 & 70.0 & 7.4 & 8.5 & 9.1 & 3.0 & 57.0 \\
4 & 100.0 & 7.5 & 8.8 & 8.8 & 4.8 & 51.0 \\
5 & 70.0 & 7.6 & 8.4 & 8.8 & 4.6 & 61.0 \\
6 & 72.7 & 6.8 & 7.7 & 7.8 & 4.6 & 60.4 \\
7 & 95.0 & 7.1 & 8.7 & 8.9 & 5.3 & 67.5 \\
8 & 71.4 & 7.0 & 8.3 & 8.8 & 4.1 & 50.8 \\
9 & 85.0 & 7.4 & 8.3 & 8.8 & 3.5 & 49.3 \\
10 & 0.0 & 5.0 & 7.3 & 8.5 & 5.1 & 55.2 \\
11 & 52.4 & 6.1 & 8.4 & 9.1 & 3.8 & 53.0 \\
12 & 85.0 & 7.5 & 8.8 & 9.1 & 4.1 & 58.8 \\
13 & 90.0 & 7.4 & 8.5 & 8.3 & 5.4 & 67.1 \\
14 & 50.0 & 5.9 & 7.8 & 8.1 & 5.4 & 65.3 \\
15 & 30.0 & 6.6 & 7.6 & 7.8 & 3.1 & 49.6 \\
16 & 90.0 & 8.0 & 9.0 & 8.7 & 3.2 & 48.3 \\
17 & 90.5 & 7.0 & 8.4 & 8.6 & 5.0 & 62.7 \\
18 & 40.0 & 6.3 & 7.5 & 8.4 & 4.6 & 62.6 \\
19 & 5.0 & 4.4 & 6.3 & 6.7 & 4.3 & 58.4 \\
\hline
\end{tabular}


Table 3

\begin{tabular}{ccccccc}
\hline & $\begin{array}{c}\text { \% Participants } \\
\text { reporting a } \\
\text { pleasant sounds } \\
\text { as subjectively } \\
\text { dominant }\end{array}$ & $\begin{array}{c}\text { Soundscape } \\
\text { quality }\end{array}$ & $\begin{array}{c}\text { Overall } \\
\text { impression }\end{array}$ & $\begin{array}{c}\text { Visual } \\
\text { quality }\end{array}$ & $\begin{array}{c}\text { Reported } \\
\text { loudness }\end{array}$ & $\begin{array}{c}\text { Sound- } \\
\text { levels } \\
\text { (dBA) }\end{array}$ \\
\hline $\begin{array}{c}\text { \% Participants } \\
\text { reporting a } \\
\text { pleasant sounds } \\
\text { as subjectively } \\
\text { dominant }\end{array}$ & 1 & - & - & - & - & - \\
$\begin{array}{c}\text { Soundscape } \\
\text { quality } \\
\begin{array}{c}\text { Overall } \\
\text { impression }\end{array}\end{array}$ & $0.811^{* *}$ & 1 & - & - & - & - \\
$\begin{array}{c}\text { Visual quality } \\
\begin{array}{c}\text { Reported } \\
\text { loudness }\end{array}\end{array}$ & $0.818^{* *}$ & $0.889^{* *}$ & 1 & - & - & - \\
$\begin{array}{c}\text { Sound-levels } \\
\text { (dBA) }\end{array}$ & 0.153 & $0.626^{* *}$ & $0.815^{* *}$ & 1 & - & - \\
\hline
\end{tabular}

${ }^{* *} \mathrm{p}$-value $<0.01$ 
Table 4

\begin{tabular}{lcccc}
\hline & People-Water-Birds & People-Water & People-Birds & Water-Birds \\
\hline Quality & $<0.01^{*}$ & $<0.01^{*}$ & $<0.01^{*}$ & $<0.01^{*}$ \\
Pleasant & $<0.01^{*}$ & $<0.01^{*}$ & $<0.01^{*}$ & $<0.01^{*}$ \\
Acute & 0.19 & - & - & - \\
Calm & 0.75 & - & - & - \\
Varied & 0.98 & - & - & - \\
Near & $<0.01^{*}$ & $<0.01^{*}$ & 0.22 & $<0.01^{*}$ \\
Natural & $<0.01^{*}$ & $<0.01^{*}$ & $<0.01^{*}$ & $<0.01^{*}$ \\
Comfortable & $<0.01^{*}$ & $<0.01^{*}$ & $<0.05^{*}$ & 0.06 \\
Relaxed & $<0.01^{*}$ & $<0.01^{*}$ & $<0.05^{*}$ & $<0.01^{*}$ \\
Steady & $<0.01^{*}$ & $<0.01^{*}$ & 0.09 & $<0.01^{*}$ \\
Usual & $<0.05^{*}$ & $<0.05^{*}$ & 0.06 & 0.91 \\
Reverberant & 0.37 & - & - & - \\
Smooth & $<0.05^{*}$ & $<0.05^{*}$ & 0.85 & $<0.01^{*}$ \\
\hline * Statistically significant difference & & &
\end{tabular}

* Statistically significant differences 
Table 5

\begin{tabular}{cccccc}
\hline Pleasant & Calm & Natural & Comfortable & Relaxed & Steady \\
\hline $0.900^{* *}$ & $0.498^{*}$ & $0.589^{* *}$ & $0.765^{* *}$ & $0.791^{* *}$ & $0.581^{* *}$ \\
& & & & & \\
Smooth & Acute & Varied & Near & Reverberant & Usual \\
\hline $0.637^{* *}$ & 0.0 .56 & 0.140 & 0.082 & 0.005 & $-0.466^{*}$ \\
\hline *p-value $<0,05,{ }^{* *}$ p-value $<0,01$ & & & & \\
\hline
\end{tabular}




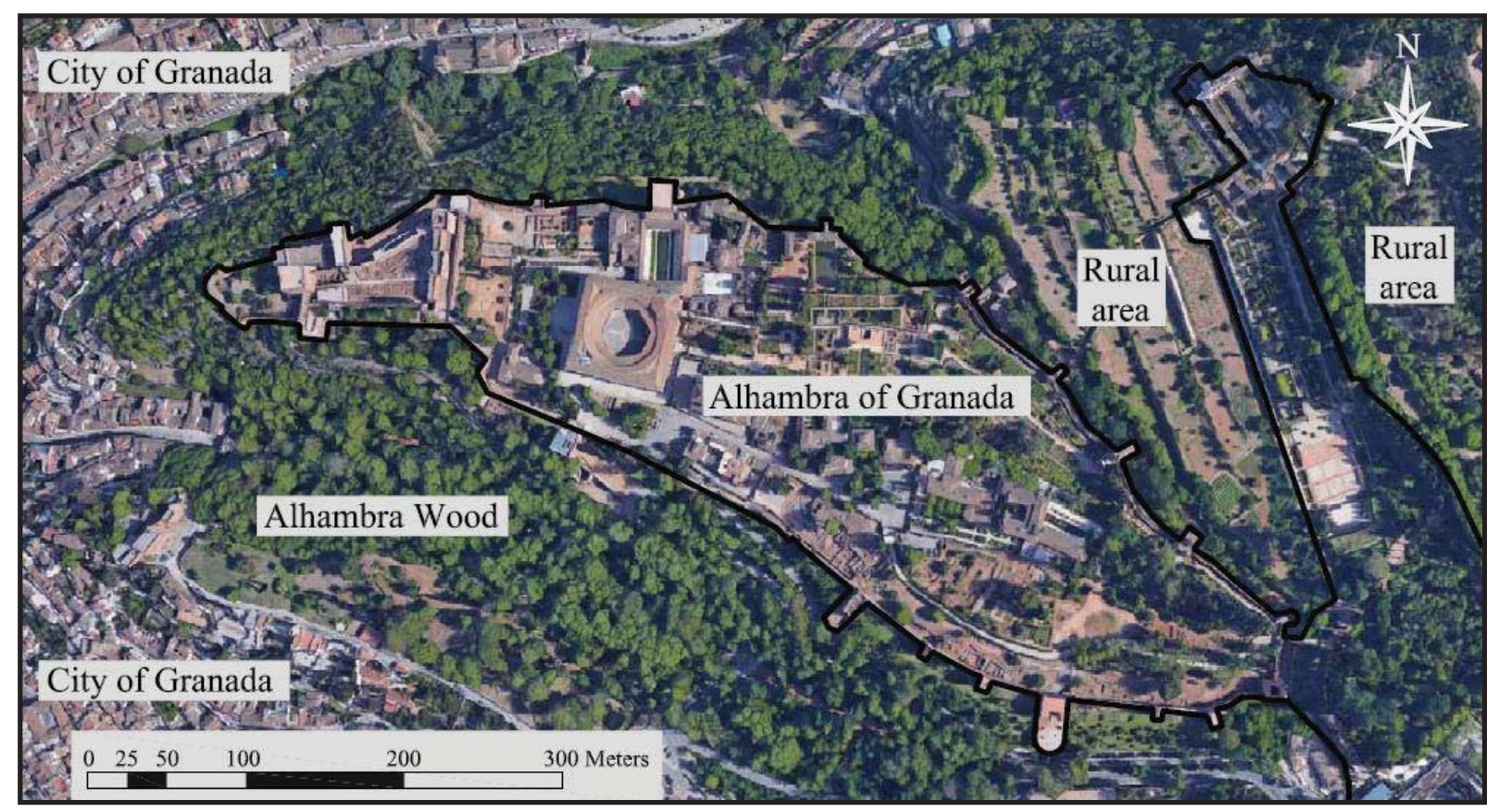

Figure 1. General view of the Alhambra monumental space and their adjacent areas. 


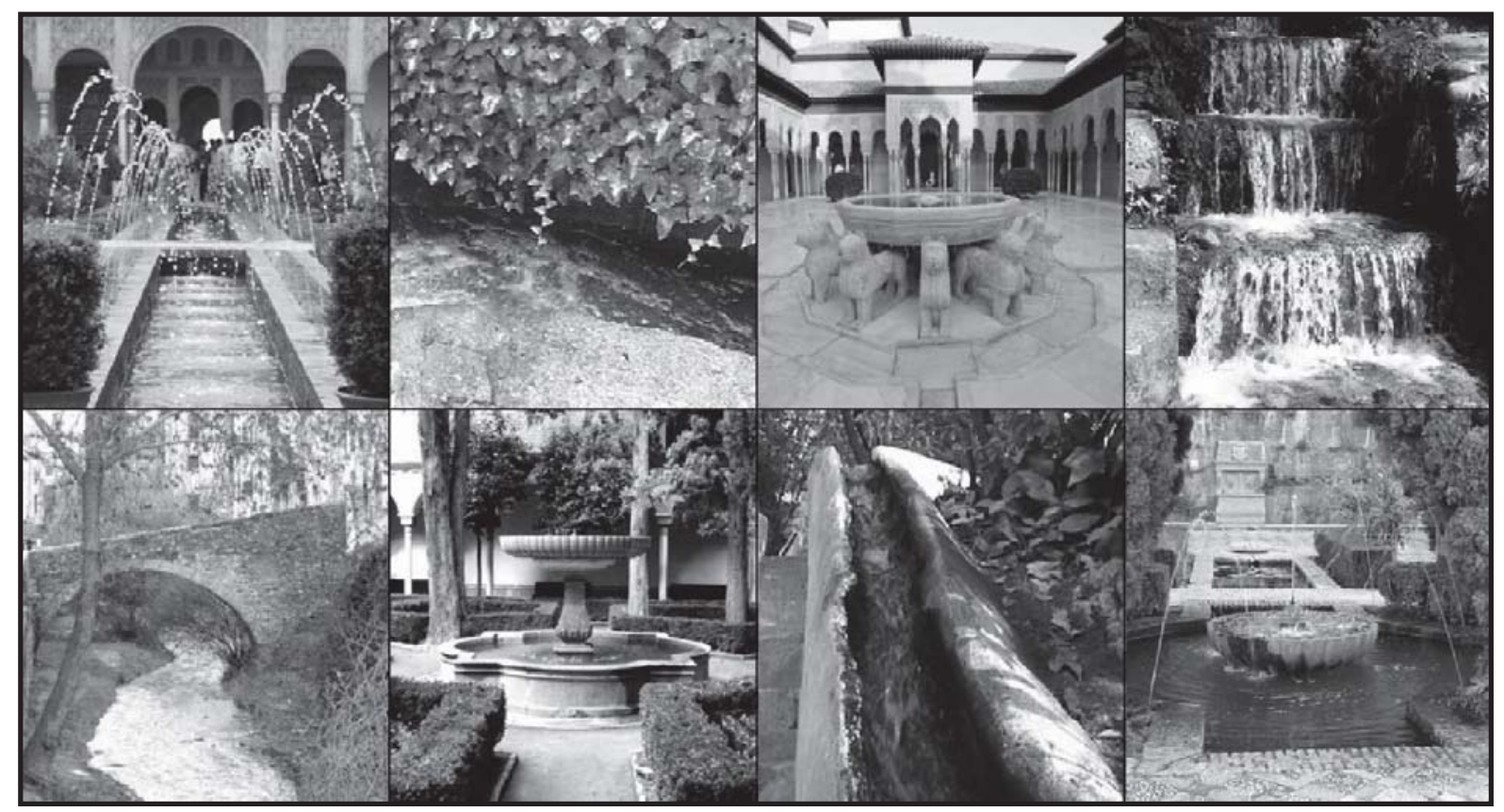

Figure 2. Representation of the diversity of water sound sources present in the Alhambra of Granada 


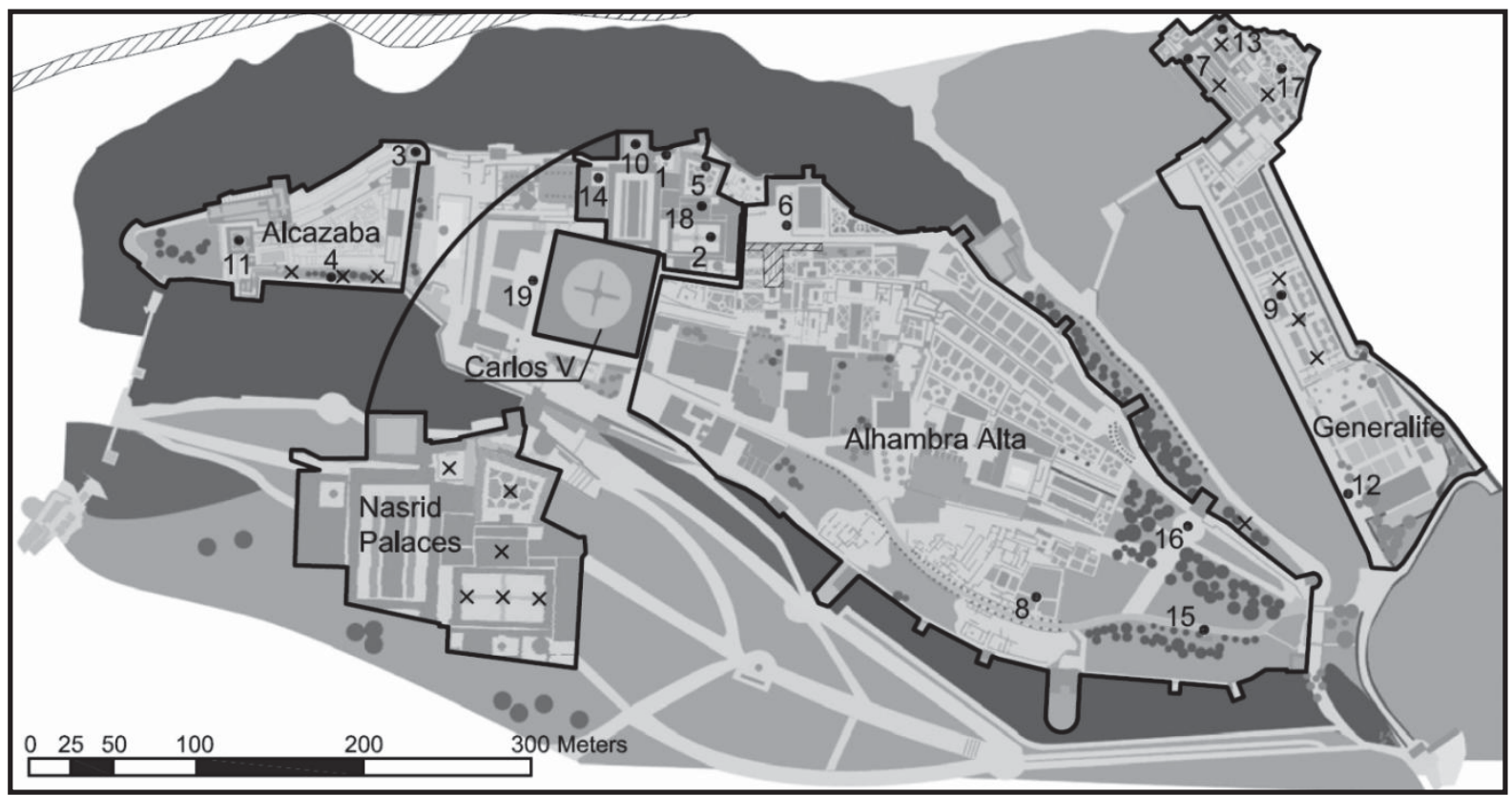

Figure 3. View of the areas within the Alhambra monumental site (see also Table 1) and selected points for data collection. It is also included those water sound sources influencing the selected measuring points. " $x$ " stands for point sound sources (waterfall, fountains etc.), scratched areas stand for surface water sound sources (rivers, irrigation ditches, etc.). 


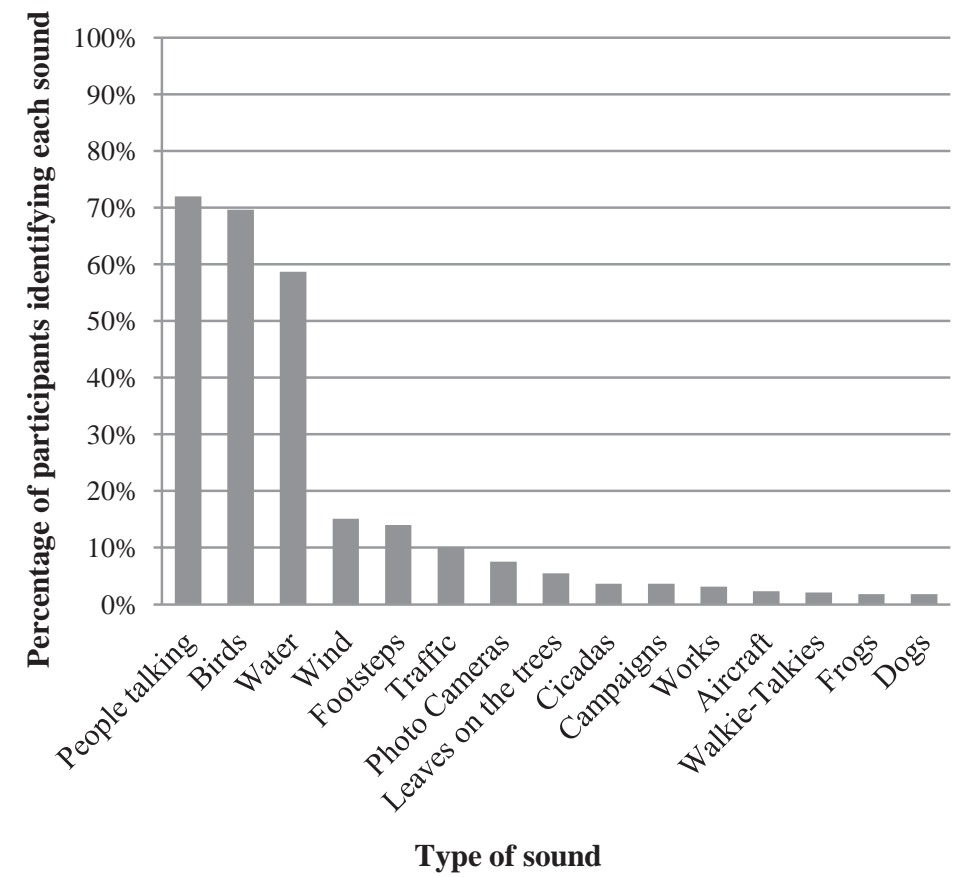

Figure 4. Set of sound sources identified and percentage of participants identifying each sound source. 


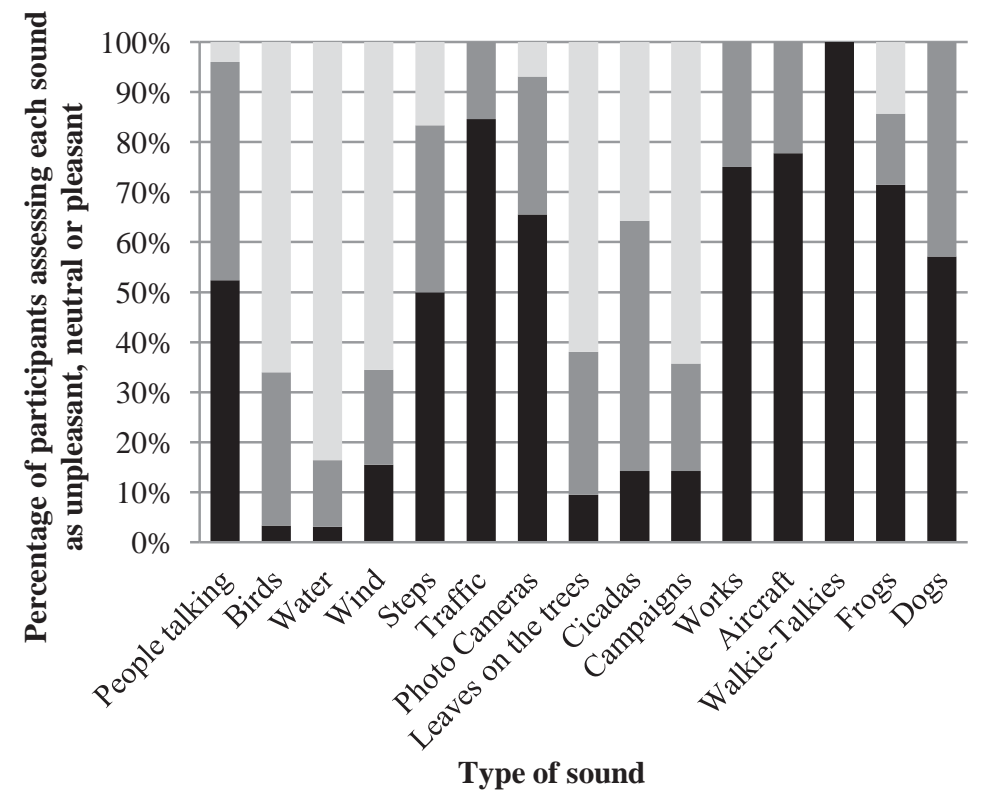

Figure 5. Subjective evaluation of the individual sounds. The segments of the bars represent the proportion of people who rated the sources as "unpleasant" (black), "neutral" (dark gray), and "pleasant" (light gray). 


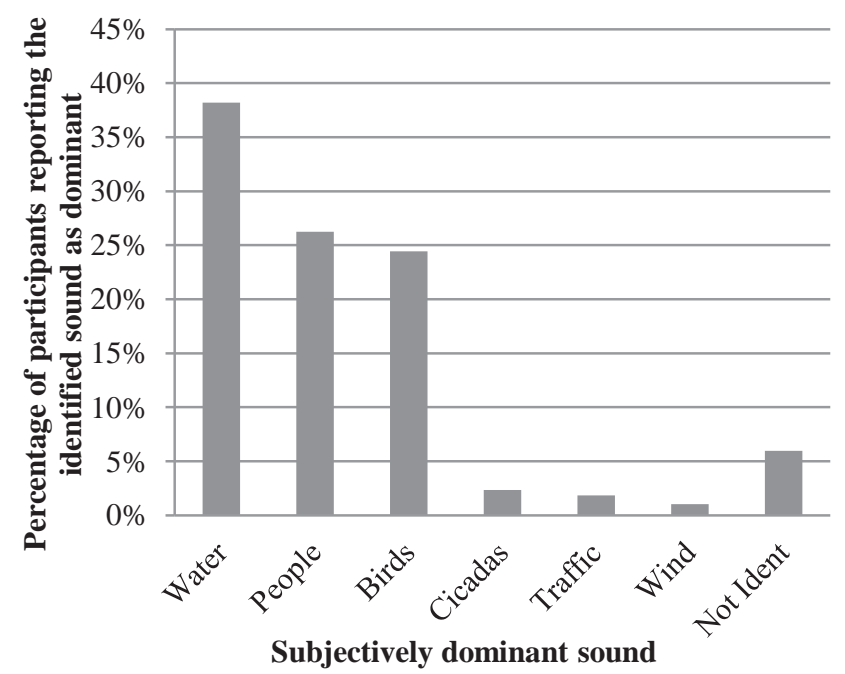

Figure 6. Percentage of participants reporting the identified sound as subjectively dominant. "Not Ident" is the percentage of participants who do not choose any sound as subjectively dominant in a given place. 


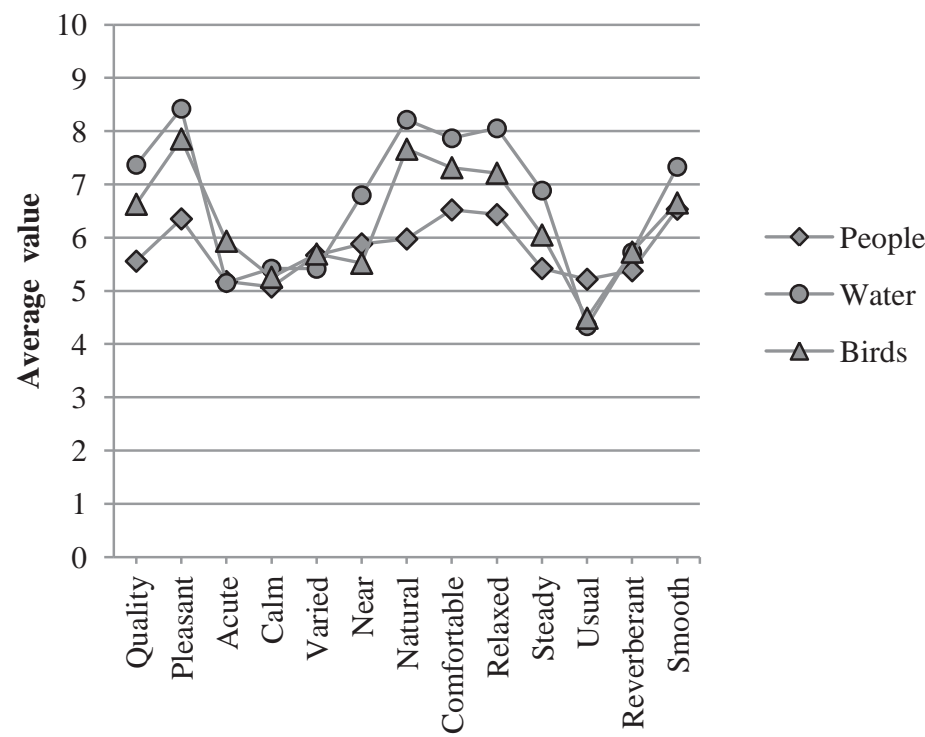

Figure 7. Average value of the reported soundscape quality and subjective attributes for the group of locations dominated by the sounds "people", "water", and "birds". 


\section{Acknowledgments}

This work has been supported by the "Ministerio de Economía y Competitividad" of Spain under project TEC2012-38883-C02-02 and CEI-BIOTIC Granada under Project P_CP_27. The authors thank the funding of the EU through the European Regional Development Funds (ERDF) and the "Patronato de la Alhambra" for supporting this research. It is also acknowledged the financial support of the "Ministerio de Educación" of Spain under PFU grant AP2012-6117. 